\title{
LA NORMA FUNDAMENTAL. ENTRE LA AUTOCONTRADICCIÓN Y LA FUTILIDAD
}

Dante Cracogna

Universidad de Buenos Aires (Argentina)

\section{El tema de la norma fundamental después de Kelsen}

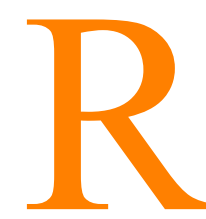

esulta remanido afirmar que el pensamiento de Kelsen experimentó una significativa evolución a lo largo de su extensa producción, y particularmente en los últimos años de su vida. Esta evolución -que ha sido considerada de diferente manera por los estudiosos ${ }^{1}$ - se advierte en distintos temas de su obra, pero es significativamente relevante en cuanto a la teoría de la norma fundamental. Ello es así puesto que la evolución que a dicha teoría atañe repercute necesariamente en toda la construcción kelseniana.

El propio Kelsen ha sostenido que la norma fundamental es central en su teoría y constituye su tema más representativo ${ }^{2}$ y de igual manera lo reconoce la doctrina en general, bastando mencionar -por todos- a Cossio quién lo puntualizó tempranamente en forma muy precisa y categórica ${ }^{3}$.

De lo dicho se desprende que toda crítica a la teoría de la norma fundamental involucra inevitablemente una crítica a la Teoría Pura en su conjunto ${ }^{4}$ y que los cambios experimentados por las ideas de Kelsen en esta materia constituyen modificaciones a la totalidad de la Teoría, aunque él mismo no lo admita expresamente.

${ }^{1}$ Cfr. Mario G. Losano, «La dottrina pura dal logicismo all'irrazionalismo», estudio introductorio a Hans Kelsen, Teoria generale delle norme, a cura di Mario G. Losano, trad. Mirella Torre, Giulio Einaudi Ed., Torino, 1985, págs. LVI y ss.

${ }^{2}$ Así lo afirma en «On The Basic Norm», California Law Review, March 1959, No 1, pág. 107 y en «El profesor Stone y la Teoría Pura del Derecho», trad. R.I.W. de Ortiz y J.A. Bacqué, en Contribuciones a la Teoría Pura del Derecho, Centro Editor de América Latina, Buenos Aires, 1969, pág. 68.

${ }^{3}$ Dijo Carlos Cossio que la norma fundamental es el «centro mismo» de la Teoría Pura del Derecho («Prólogo» a Hans Kelsen, La Teoría Pura del Derecho. Introducción a la problemática científica del derecho, trad. J. Tejerina, Losada, Buenos Aires, 1946, pág. 9).

${ }^{4}$ Cfr. Dante Cracogna, «En tomo a la norma básica», en Anuario de Filosofía Jurídica y Social, No 13, Abeledo-Perrot, Buenos Aires, 1993, págs. 193 y ss. Especialmente demostrativa de este aserto es la crítica de Albert Calsamiglia en Kelsen y la crisis de la ciencia jurídica, Ariel, Barcelona, 1978. 
A casi un cuarto de siglo de la muerte de Kelsen, cuando su producción ya ha sido motivo de exhaustivo estudio, tanto en sí misma y a lo largo de su evolución como en relación con las distintas teorías contemporáneas y posteriores a la suya, continúa siendo de interés -y quizás más que antes- la reflexión crítica acerca de sus presupuestos y postulados fundamentales. Tal vez ahora, pudiendo apreciar en perspectiva las mutaciones del pensamiento kelseniano, resulte más fundado efectuar una evaluación de su significado procurando su comprensión más cabal.

\section{Significado inicial y significado final de la norma fundamental en la teoría de Kelsen}

La cuestión central en tomo a la norma fundamental finca en su diferente significado en la obra de Kelsen que culmina con la segunda edición de la Teoría Pura del Derecho y en la etapa posterior. Tal diferencia lleva, incluso, a preguntar: ¿cuál norma fundamental? pues, evidentemente, bajo una misma denominación se cobijan dos diferentes objetos.

En la primera etapa el sentido es claramente kantiano, conforme con el cual la norma fundamental aparece como una verdadera categoría que posibilita el conocimiento del derecho como un sistema o conjunto de normas con fundamentación unitaria. Cossio puso énfasis en este significado gnoseológico, destacando la importancia que para el conocimiento jurídico tenía esta noción original de Kelsen ${ }^{5}$. Bobbio, por su parte, hizo hincapié en el aporte fundamental de Kelsen a la concepción del Derecho como sistema, en la cual desempeña un papel central la norma fundamental ${ }^{6}$.

En la segunda edición de la Teoría Pura se lee este párrafo revelador: «puede designarse a la norma fundante básica, tal como es representada por la ciencia del derecho, y si cabe recurrir per analogiam a un concepto de la teoría kantiana del conocimiento, como la condición lógico-trascendental de esa interpretación.» $\mathrm{Y}$ se agrega, explicando y precisando el sentido de la oración: "Así como Kant pregunta cómo es posible una interpretación, libre de toda metafísica, de los hechos dados a nuestros sentidos en las leyes naturales formuladas por la ciencia natural, la teoría pura del derecho pregunta: ¿cómo es posible la interpretación, que no eche mano de autoridades metajurídicas, como dios o la naturaleza, del sentido subjetivo de ciertos hechos, como un sistema de normas jurídicas válidas objetivamente, describi-

${ }^{5}$ Dante Cracogna, «Acerca de la norma fundamental en Cossio», en Anuario de Filosofía Jurídica y Social, No 7, Abeledo-Perrot, Buenos Aires, 1987, pág. 137 y ss.

${ }^{6}$ Norberto Bobbio, «Estructura y función en la teoría del derecho de Kelsen», en Contribución a la Teoría del Derecho, trad. y estudio preliminar de Alfonso Ruiz Miguel, Fernando Torres Editor, Valencia, 1980, pág. 251 . 
bles en enunciados jurídicos? La respuesta gnoseológica de la teoría pura del derecho es: bajo condición de que se presuponga la norma fundante básica "uno debe comportarse como la constitución lo prescribe" "...»

En la última etapa kelseniana la norma fundamental (como toda otra norma jurídica) es el sentido de un acto de voluntad ${ }^{8}$, por lo cual resulta necesario encontrar una voluntad detrás de ella. Como la norma fundamental no es norma positiva (puesta) su naturaleza es la de una ficción; por ende, detrás de ella debe existir una voluntad también ficticia. Dice reveladoramente la obra póstuma de Kelsen: «La norma fundamental de un ordenamiento moral o jurídico positivo es, como resulta de lo antedicho, una norma no positiva sino simplemente pensada y, por tanto, una norma ficticia que es el sentido de un acto de voluntad no real sino también ficticio. Como tal esa es una ficción auténtica o "propia" en el sentido de la filosofía del "como si" de Vaihinger, ficción caracterizada no solo por una contradicción con la realidad sino por una contradicción interna.» Más adelante concluye diciendo: «Se advierte, por tanto, que la norma fundamental en el sentido de la filosofía del "como si" de Vaihinger no es una hipótesis, como antes la definí yo mismo, sino una ficción que se distingue de una hipótesis por el hecho que está acompañada, o debe estarlo, de la conciencia de que no corresponde a la realidad $\left.{ }^{9}.\right\rangle$

Resulta evidente que se trata de dos nociones muy diversas, por lo que es imperioso distinguirlas ya que Kelsen continúa llamándolas de la misma manera a pesar de que él mismo se encargó de puntualizar sus diferencias ${ }^{10}$. De forma, pues, que necesariamente deben formularse precisiones cuando se hace referencia a esta cuestión y con más razón cuando se le dirigen críticas.

\section{3. ¿Qué queda de la norma fundamental original?}

Cabe preguntarse si todavía tiene sentido hablar de la norma fundamental utilizando esta denominación empleada por Kelsen en su primera etapa y hasta 1960 o si, por el contrario, ya no debe utilizársela con valor actual sino solamente con sentido histórico, es decir referida a un determinado momento del pensamiento kelseniano. En suma: ¿puede legítimamente conti-

${ }^{7}$ Hans Kelsen, Teoría Pura del Derecho, 2a. edición, trad. de Roberto Vernengo, UNAM, México, 1979, págs. 209-210.

${ }^{8}$ Hans Kelsen, Teoria generale delle norme, cit., pág. 3.

${ }^{9}$ Hans Kelsen, Teoria generale delle norme, cit., págs. 434-435.

${ }^{10}$ Así lo sostuvo en el recordado coloquio de Salzburgo de 1962 y posteriormente en el artículo «Die Funktion der Verfassung», Forum, 11, Wien, 1964, traducido y publicado por Ian Stewart en su artículo «The Basic Norm as Fiction», en Juridical Review, Edinburgh, N 25, 1980, págs. 214 yss. 
nuar usándose una expresión que nació con un cierto y preciso significado para nombrar otra cosa distinta?

Sin caer en nominalismo, puede afirmarse que la norma fundamental posterior a 1960 ya no es, en rigor, «la» norma fundamental pese a seguir llamándola de igual manera.

Sentado que se trata de cosas diferentes cabe, entonces, preguntarse si queda algo de la norma fundamental original o si ésta se ha esfumado por completo al conjuro de las nuevas ideas de su creador; si el voluntarismo de nuevo cuño ha barrido totalmente el antiguo concepto o bien permanece todavía algo de aquél. Y en caso de afirmarse la subsistencia de algún remanente ¿de qué se trata?

La tónica final de Kelsen parece orientarse hacia un cierto irracionalismo de carácter voluntarista, como lo llama Losano ${ }^{11}$, lo cual equivale a una variante del realismo toda vez que la voluntad es un dato fáctico, propio de la realidad. De tal suerte, el sentido esencial de la norma fundamental original desaparece, puesto que ya no se trata de un supuesto gnoseológico a la manera de las categorías kantianas.

Sin embargo, no es sólo ésa la función atribuida a la norma fundamental. En realidad, como dice Vernengo ${ }^{12}$, son tantas las funciones adjudicadas a esta norma que solamente por milagro podría cumplirlas. Por lo tanto, es dable pensar que aun habiendo perdido su carácter principal, sobreviva alguna otra función propia de ella que justifique su permanencia.

\section{La unidad del Derecho y la función sistematizadora}

Parecería que la norma fundamental continuara siendo necesaria para cumplir el cometido de fundar la unidad del derecho y determinar el criterio de identificación de normas y ordenamientos jurídicos.

En efecto, habiendo sido despojada de su naturaleza original de hipótesis o supuesto gnoseológico, queda en pie, no obstante, la función unificadora, ordenadora y sistematizadora de la norma fundamental. Vale decir que ésta continúa desempeñando una tarea de significativa importancia teórica en el campo de la ciencia jurídica.

Dicha tarea ha sido reconocida aún por los críticos de Kelsen y de su teoría de la norma fundamental, siendo destacable el caso de Ross ${ }^{13}$. En suma, se reconoce que para poder hablar de sistema jurídico es necesario re-

LIX.

${ }^{11}$ Cfr. Mario G. Losano, La dottrina pura del diritto dal logicismo all’irrazionalismo, cit., pág.

${ }^{12}$ Roberto J. Vernengo, «La función sistemática de la norma fundamental», en Revista Jurídica de Buenos Aires, 1960, I-II, pág. 220.

${ }^{13}$ Dante Cracogna, «Sistema jurídico, validez y norma fundamental en Alf Ross», en Revista de Ciencias Sociales, Universidad de Valparaíso, No 25, T. I, págs. 227 y ss. 
currir a la noción de la norma fundamental, aunque simultáneamente se descalifiquen otros aspectos de ella o se critique -básicamente- la naturaleza que le adjudicó Kelsen, sea en su origen o en su etapa final.

La cuestión es que con Kelsen se instaló en forma definitiva dentro del campo del estudio científico del derecho, la consideración de éste como sistema de normas. Alchourrón y Bulygin ${ }^{14}$ lo señalan claramente cuando se refieren al carácter de la ciencia jurídica a la que califican como sistematizadora.

\section{Conclusión}

Las numerosas y diversas críticas que se han dirigido a la norma fundamental en su concepción vigente hasta 1960 han solido estar basadas en la naturaleza de supuesto que ella tenía entonces. Las críticas que se le han dirigido con respecto a la última etapa de Kelsen apuntan -en cambio- a cuestionar su inconsistencia con la primera, descalificándola por contradictoria o bien postulando, sencillamente, su eliminación por supuestamente innecesaria o superflua.

En rigor, más allá de cuestionamientos ideológicos o fundados en apreciaciones de orden filosófico o, inclusive, semántico, resulta difícilmente cuestionable la utilidad teórica que presta a la labor científico jurídica la norma fundamental, particularmente por su aporte a la sistematización del objeto del conocimiento jurídico. Su valor epistemológico resulta así relevante.

${ }^{14}$ Carlos E, Alchourrón y Eugenio Bulygin, Introducción a la metodología de las ciencias jurídicas y sociales, Astrea, Buenos Aires, 1975, pág. 113. 
DOXA 21-II (1998) 